\title{
Ocean Swells along the Global Coastlines and Their Climate Projections for the Twenty-First Century $\mathscr{O}$
}

\author{
ANGEL AMORES \\ Instituto Mediterráneo de Estudios Avanzados (UIB-CSIC), Esporles, Spain \\ MARTA MARCOS \\ Instituto Mediterráneo de Estudios Avanzados (UIB-CSIC), Esporles, and Departament de Física, Universitat de les Illes Balears, \\ Edifici Mateu Orfila, Palma, Spain
}

(Manuscript received 20 March 2019, in final form 6 August 2019)

\begin{abstract}
Remotely generated swell waves are the dominant contributor of the coastal wind-wave climate along most of the world coastlines. In this work we describe the characteristics of swells from a coastal perspective. We identify the main regions of formation of swell waves at present and during the late twenty-first century under the RCP8.5 emissions/climate change scenario. We have applied an algorithm that allows one to unequivocally differentiate the swell component from the local wind-waves for a global wave hindcast and for eight CMIP5 state-of-the-art wave model climate projections. We have identified four different regions of swell formation, two in each hemisphere, with the Southern Ocean being by far the main region of swell generation. By the end of this century, the number of swell events generated in the Northern Hemisphere is expected to decrease while the opposite is projected to occur in the Southern Hemisphere. The increase in the Southern Hemisphere is directly associated with a poleward movement and intensification of the wind belts projected by atmospheric climate models.
\end{abstract}

\section{Introduction}

Ocean wind-waves are one of the key mechanisms modulating the coastlines as well as a major contributor to coastal hazards. Changes in wind-waves associated with climate variability have been described in the past at different time scales [e.g., Hemer et al. (2010) during recent decades and Gulev et al. (2003) in the last century]. These are relevant to coastal evolution as well as in the deep water, for example for marine offshore systems (such as oil platforms that cannot effectively embark oil under large swells). Likewise, projections of climate change-driven variations of wind-waves have been shown to be significant in many regions of the world oceans (Hemer et al. 2013a). The potential coastal impacts of these projected wind-waves are expected to increase as they will evolve together with rising mean

Supplemental information related to this paper is available at the Journals Online website: https://doi.org/10.1175/JCLI-D-190216.s1.

Corresponding author: Angel Amores, angel.amores@uib.es sea level that will exacerbate the effects of extreme events and coastal flooding.

Close to their formation area, wind-waves are strongly coupled to the local wind field and they are called windsea. Once they leave the formation region, they become swell, they are no longer coupled to the wind, and they can travel vast distances (e.g., Ardhuin et al. 2009). The separation between the two components is not straightforward; actually, datasets from voluntary observing ships are the only source of observations that initially separate estimates from wind-seas and swells, although they are not free of uncertainties (Gulev et al. 2003). Both types, wind-sea and swell, play a significant role in many physical processes such as transfer of momentum or heat between the atmosphere and the ocean (e.g., Cavaleri et al. 2012), being the major contribution to the ocean mixing in the upper layers $(\sim 100 \mathrm{~m})$.

There are several studies analyzing the present climate (Semedo et al. 2011; Young 1999) and future

Publisher's Note: This article was revised on 27 February 2020 so the Acknowledgments section could include the primary funder of the study that was omitted when originally published. 
projections of ocean wind-waves in the global ocean (Fan et al. 2014; Hemer et al. 2013a,b; Mori et al. 2013), mostly on the basis of numerical wave models. Based on in situ observations, Gulev and Grigorieva (2006) found different patterns of wind-seas and swells in the North Atlantic and Pacific Oceans and linked them to local winds and cyclone frequency, respectively. Despite their different methods and datasets used, earlier studies conclude that the swell component of the ocean windwaves dominates in the global ocean. However, no attempt has been done yet to unequivocally separate swells from the ocean wind-seas to study their present characteristics and projected changes based on numerical wave models. Instead, these studies usually rely on identifying the frequency-wavenumber spectral bin containing the peak frequency of the swell. This is despite the complex interaction between wind-sea and swell components, which is poorly captured by state-ofthe-art numerical wave models.

In this work we apply a recently developed technique to state-of-the-art wind-wave model reanalysis and climate projections for the twenty-first century that allows one to determine the origin and the formation time of a swell event using the dispersive nature of the ocean waves traveling over deep water (Portilla 2012). We focus on the swell events reaching the global coastlines and we also identify the major regions where these swells are formed, exploring their projected changes under climate change with the representative concentration pathway RCP8.5 scenario. Coastal areas are regions of high interest for several reasons including, but not limited to, 1) high population densities are gathered along the coastlines (Small and Nicholls 2003), 2) lowlying coastal areas such as small islands may no longer be habitable under the combined effect of projected sea level rise plus swell events of unchanged or increased magnitude, and 3) changes in the oceanic swell component could affect the operation and design of coastal industries, such as harbors or power plants (nuclear or renewable energy), and ecosystems. This work represents the first attempt to explore the present-day and projected impacts of swells (and not the entire windwave spectrum) along the world coastlines.

\section{Data and methods}

\section{a. Global wind-wave datasets}

We use a set of global wind-wave simulations generated using the WAVEWATCH III wave model (version 3.14; Tolman 2009) with spatial resolution of $1^{\circ} \times 1^{\circ}$. All simulations are available through the Centre for Australian Weather and Climate Research (CAWCR) global wind-wave twenty-first-century climate projections freely distributed by the Commonwealth Scientific and Industrial Research Organisation (CSIRO) data server (Hemer et al. 2015). They contain, among other variables, significant wave height $H_{s}$, peak wave frequency (which we convert into peak wave period $T_{p}$ ), and peak wave direction $D_{p}$. This set composes a hindcast, representing the observed wave climate of the last few decades, and historical runs and projections during the twenty-first century. We have used the hindcast run forced with the National Centers for Environmental Prediction CFSR (Saha et al. 2010; the expansions of model and other acronyms used in this paper may be found at https://www.ametsoc.org./PubsAcronymList), covering the period from 1979 to 2009 with a temporal resolution of $1 \mathrm{~h}$ (referred to as CFSR hereinafter). Future wave conditions were evaluated using the climate projections of an ensemble of eight different CMIP5 models (ACCESS1.0, BCC-CSM1.1, CNRM-CM5, GFDLESM2M, HadGEM2-ES, INM-CM4, MIROC5, and MRICGCM3) included in the dataset. Three different time periods are covered by these projections, with a temporal resolution of $6 \mathrm{~h}$. First, historical runs are available spanning the time period 1980-2005. These runs are used to assess possible biases in present-day wave conditions provided by the climate models with respect to the CFSR hindcast. Then, projected wave changes are available for the middle (2026-45) and late (2081-2100) twenty-first century and are run under two different emission scenarios, RCP4.5 and RCP8.5. A detailed description of the wave climate dataset can be found in Hemer et al. (2013b).

\section{b. Selection of coastal points}

The coarse spatial resolution of the wave climate simulations $\left(1^{\circ}\right)$ is a poor representation of the actual coastlines, especially in small oceanic islands whose size is smaller than the grid resolution. However, even though there are no land grid points in these regions, the coarse-resolution bathymetry does represent partly their features and, consequently, the wave field is modified accordingly (see the shadow effect caused by the islands in Movies 1 and 2 in the online supplemental material). Therefore, to have a better representation of the coastlines, we have used the coastline from the Open Street Map Data website (available at https:// osmdata.openstreetmap.de/data/coastlines.html). In this coastline, all of the enclosed and semi-enclosed seas, where the remotely formed ocean swells are expected to play a minor role, were removed (i.e., the Mediterranean Sea, the Baltic Sea, the Gulf of California, and all of the seas between Indonesia and the Philippines). Also, we have retained only the pieces of land with an area larger than $1 \mathrm{~km}^{2}$. For each individual point of the 
coastline, the valid wave model grid point (a model grid point was considered to be valid if it had an assigned value at every time step for all model projections) closer than one-half of the model grid resolution (i.e., $0.5^{\circ}$ ) was assigned. With this procedure and after removing repeated points, a total of 1728 points were finally selected as coastal points for the analyses. These points are evenly distributed along the continental and island coasts at the tropics and midlatitudes. However, the regions located at high latitudes (above $\sim 50^{\circ} \mathrm{N} / \mathrm{S}$ ) are misrepresented because of the lack of valid points in all of the numerical simulations.

It is important to remark that the models used cannot model nearshore evolution because of their limited spatial resolution. Thus, the wave features described in this study have to be understood as offshore conditions but in proximity to coasts.

\section{c. Determination of the origin of swell events}

Swells are able to travel long distances from their originating location almost without being disturbed because of their small energy dissipation. When swell waves reach a coastal region far from their generation zone, longer waves with higher periods arrive first, followed by shorter waves with lower periods. Taking advantage of this dispersive nature of the ocean swells, Portilla (2012) described an algorithm to determine their formation distance and time. This method is summarized in the following.

The group velocity of waves in deep water is

$$
c_{g}=g /(4 \pi f) \text {, }
$$

where $g$ is the gravity and $f$ is the wave frequency. Assuming that the distance that the different wave frequencies have traveled when arriving to the coastal point is the same and that they originated at the same time, it is found that the distance $d$ to their origin can be computed as

$$
d=\frac{g}{4 \pi} \frac{\partial t}{\partial f}
$$

and the time since their formation can be determined in a similar manner. Once the formation distance is computed, the region where waves were generated can be delimited by using the wave peak direction and assuming that the waves travel along great circles.

Although theoretically it is straightforward to compute the distance and time of formation of an oceanic swell event following the equations above, in practice swells are modified by the presence of geographic features and change their direction during their travel across the ocean. For example, one oceanic swell event traveling through a set of islands would be modified by the bathymetry, causing reflection or diffraction and modifying the wave properties, including the direction of propagation (see Movies 1 and 2 in the online supplemental material). For that reason, some additional steps were included in the algorithm to determine the location and time of formation of a swell event.

The arrival of a swell event reaching a coastal point is reflected as an abrupt increase of the peak period followed by a "linear" decrease (Fig. 1a). To identify the possible swell events with a clear (i.e., unaltered) origin region, the following steps were defined after exploring the swell characteristics and later applied to the peak period time series:

1) The increase in the peak period at the beginning of a possible swell event must be at least $1 \mathrm{~s}$ in $6 \mathrm{~h}$.

2) The derivative with respect to time of the peak period time series after the maximum, $\partial T_{p} / \partial t$, must be negative during the swell event (i.e., the peak period should monotonically decrease with time).

3) The value of the $\partial T_{p} / \partial t$ must be greater than $-1 \times$ $10^{-4} \mathrm{~s} \mathrm{~s}^{-1}$. This condition implies that the peak period cannot decrease "extremely fast." For example, with this condition, a decrease in the peak period of $10 \mathrm{~s}$ ( similar to the first red event in Fig. 1a) could not happen faster than $27 \mathrm{~h}$. This threshold has been chosen after exploring the values of $\Delta T_{p} / \Delta t$ for a combination of formation distances and peak periods using Eq. (2) (see Fig. SM1 in the online supplemental material; the region of swell event missed by the application of this criterion corresponds to the area under the black line).

4) The maximum peak period must be larger than $8 \mathrm{~s}$. Again, this threshold was established after evaluating the distribution of the most probable peak period for the CFSR hindcast shown in Fig. 2a.

5) The swell event must last at least $24 \mathrm{~h}$.

6) During the duration of the event, the peak direction $D_{p}$ (Fig. 1b) cannot vary by more than $10^{\circ}$.

With the sections of the time series of peak period that fulfilled the above criteria, the distance to the origin of swell events (and its associated error) was computed following Eq. (2). To obtain comparable errors for all swell events, irrespective of duration, the linear regression of $\partial f_{p} / \partial t$ needed to compute the formation distance $d$ was calculated using the interval of $18 \mathrm{~h}$ after the beginning of the event. Among all the resulting swell events, we only retained those whose relative error in the formation distance $d$ was smaller than $20 \%$ (red lines in Figs. 1a and 1b). For each selected swell event reaching any of the coastal points, we delimited the region of formation, its error, and the time of formation 

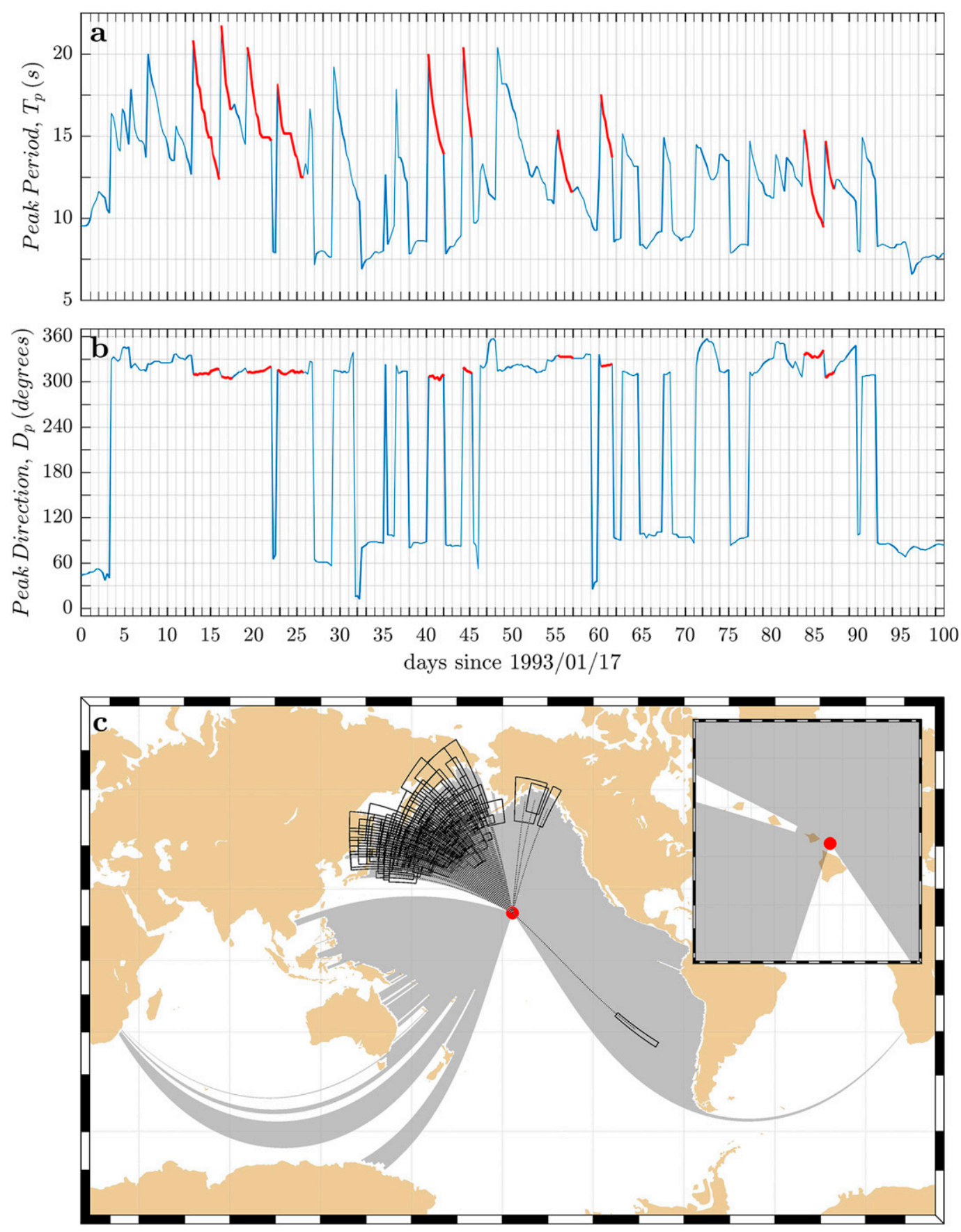

FIG. 1. (a) 100-day time series of peak (a) period and (b) direction of the ACCESS1.0 historical run at a grid point in the Hawaiian Islands. The swell events identified by the algorithm are indicated in red. (c) Map of the regions where a swell event reaching the target grid point (red dot) can be generated (gray shadow). The black dotted lines and solid black squares indicate the path and origin, respectively, of a single swell event reaching the analyzed point [those events indicated in red in (a) and (b)]. The inset in (c) is a zoom of the studied point (red dot) and the possible swell origin location (gray shadow).

[see an example in Fig. 1c of all of the swell events (black boxes) obtained for one coastal point of the Hawaiian Islands for the historical run of the ACCESS1.0 model]. As a final step, a filter of possible origins was applied and only those swell events traveling along great circles without reflection or diffraction were considered. To do so, we removed regions of formation shadowed by the presence of land (Pérez et al. 2014). We constructed an 
area of possible origins for each coastal point (as an example, this area for a coastal point near Big Island, Hawaii, is shown as a shadowed region in Fig. 1c) and we only retained the swell events whose area of origin (including the uncertainties) lay at least $50 \%$ inside the possible origin region. In other words, we have analyzed only those events that reach the coastlines and have not suffered any diffraction, refraction, or reflection during their time travel from their formation area. It is important to remark that several swell systems could reach a coastal point at the same time, in which case, given the nature of the model outputs, only the most energetic event would be represented in the time series of peak period. In other words, our method would be missing secondary and other swell peaks. In addition, in wind-sea-dominated regions, our algorithm could underestimate the total number of swell events if these are less energetic than the wind-sea component. Even in this case, however, we expect that the relative changes of the swell events (i.e., the difference between the end of the twenty-first century and present day) would not be affected by this underestimation, since both time periods would be equally underestimated (unless the future swell events become more energetic than the local wind sea, in which case there will be a high increase in the number of swell events by the end of the twenty-first century). In consequence, we want to stress that the number of swell events detected at each individual coastal grid point might be underestimated but never overestimated.

The procedure described above was applied to each time series of peak period and peak direction at the 1728 coastal points available for the CFSR hindcast, the eight historical runs, the eight mid-twenty-first-century runs, and the eight end-of-twenty-first-century runs. As a result, a spatiotemporal distribution of the origin of the swell events for each run was obtained (see Movie 3 in the online supplemental material). We have summarized all this information into a single map of the spatial distribution of the swell origins for each wave simulation as follows. First, we built a $0.25^{\circ}$ grid on which, for each day, we assigned a value of 1 if there was one or more swell events within that one day and 0 otherwise. Note that swell events may be associated with several coastal points. These daily maps were added together to account for the total number of swell events within each $0.25^{\circ}$ box. Note that the absolute number of swell events could be overestimated. A single storm could originate a swell event affecting, for example, $n$ coastal locations, so it could be detected $n$ different times. If the origin time determined for these $n$ "different" swell events corresponded to the same day, this event would be counted as one single swell; otherwise, this swell event could be double counted. However, we are not interested in the absolute values (we are also missing swell events, for example, by assuming that they are not reflected or diffracted) but in their future relative changes.

\section{Results}

\section{a. Hindcast coastal wave conditions (1979-2009)}

Figure 2 displays the average coastal wave conditions from the CFSR hindcast. The geographical distribution of the most probable peak period along the global coastlines (Fig. 2a) shows a pattern similar to the mean wave period map described in Hemer and Trenham (2016), where larger values dominate in the eastern coasts of the $\mathrm{Pa}$ cific, Atlantic, and Indian Oceans. These largest values (reaching more than $15 \mathrm{~s}$ ) are clearly visible all along the western coast of America $\left(50^{\circ} \mathrm{N}-55^{\circ} \mathrm{S}\right)$ and all along the eastern coast of the Indian Ocean, from Bangladesh $\left(22^{\circ} \mathrm{N}\right)$ to Tasmania $\left(43^{\circ} \mathrm{S}\right)$, excluding the northern coast of Australia. Similar peak periods are found in the western islands of Maldives and the British Indian Ocean Territory $\left(72^{\circ} \mathrm{W}, 8^{\circ} \mathrm{N}-8^{\circ} \mathrm{S}\right)$ and in the South Pacific islands, such as French Polynesia $\left(150^{\circ} \mathrm{W}, 17^{\circ} \mathrm{S}\right)$. Slightly smaller values of most probable peak period (around 12$13 \mathrm{~s}$ ) are found in the eastern coast of Africa, from Senegal $\left(14^{\circ} \mathrm{N}\right)$ to South Africa $\left(35^{\circ} \mathrm{N}\right)$. The smaller values of peak period (between 2 and $7 \mathrm{~s}$ ) correspond to the eastern coast of America, including the Caribbean Sea, while the eastern coast of Africa and western coast of the Pacific Ocean range between 7 and $9 \mathrm{~s}$. The distribution of most probable peak periods in regions such as the Hawaiian Islands, the Cape Verde Islands, or Madagascar catches the eye because of its polarized structure, with large values $(>13 \mathrm{~s})$ in one part of the region and smaller values $(<8 \mathrm{~s})$ in the opposite part.

The number of swell events per year reaching the coastal points and determined as described in section $2 \mathrm{c}$ is mapped in Fig. 2b. The coastal regions with larger number of swell events per year (more than 30 events) are located in the intertropical areas $\left(25^{\circ} \mathrm{S}-25^{\circ} \mathrm{N}\right)$ of the eastern coasts of the Pacific, Atlantic, and Indian Oceans. These are also the regions where swell events last longer (more than 48h; Fig. 2c). Away from these areas, the number of swell events and their duration in time decrease considerably. Figure $2 \mathrm{~d}$ shows the intensity of the events in terms of median significant wave height. The regions with larger values $(>2 \mathrm{~m})$ are the western coasts of the continents close to the Southern Ocean, such as the coast of Chile, South Africa, or Australia. The small islands located southeast of Africa are the regions with larger median wave height, with values larger than $3 \mathrm{~m}$.

All of the information provided in the maps in Fig. 2 is summarized in online supplemental Fig. SM2. The most 


\section{CFSR Hindcast}
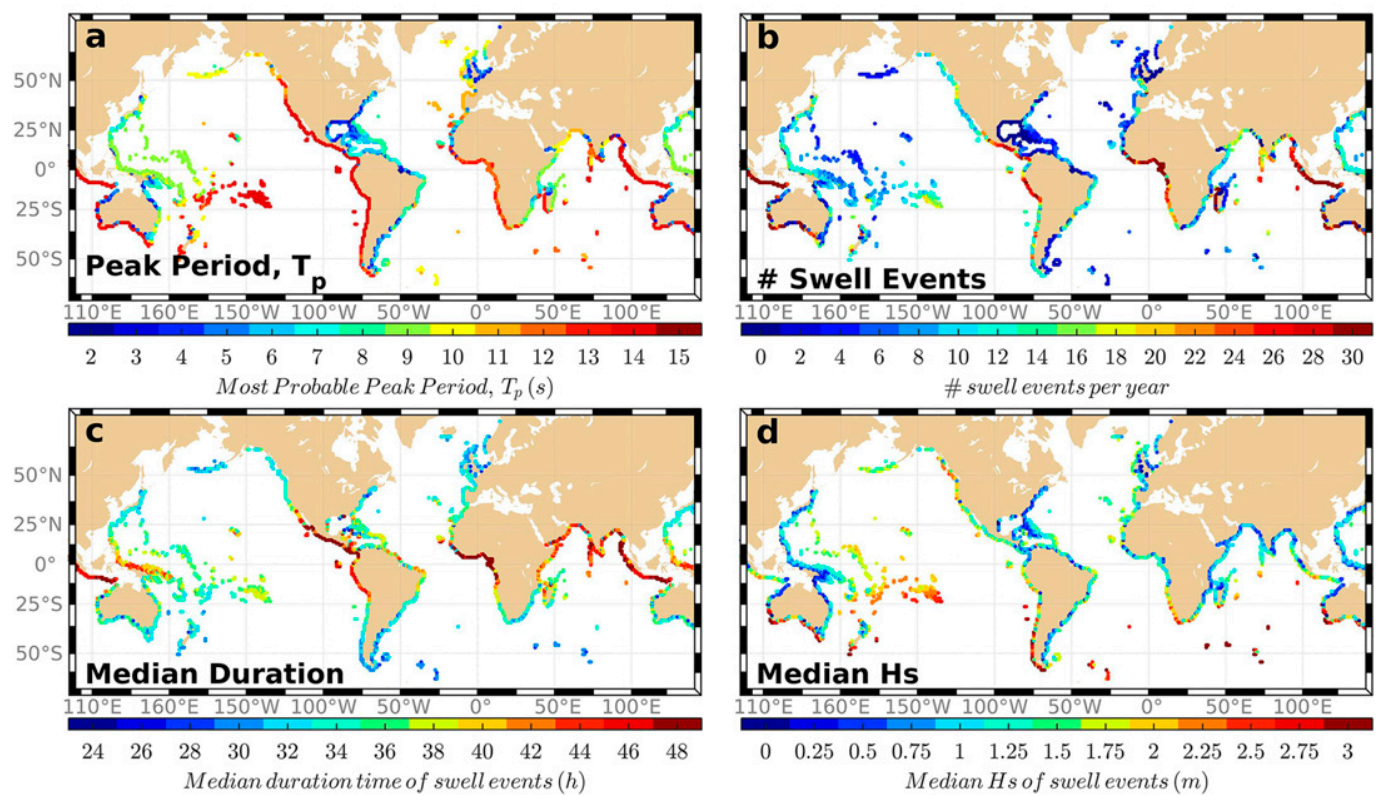

FIG. 2. Computed from CFSR hindcast (1979-2009), the (a) most likely peak period, (b) number of swell events, (c) median duration of the swell events registered at each coastal point, and (d) median significant wave height $H_{s}$ of the swell events.

probable peak period distribution (Fig. 2a) shows that there is a larger number of coastal points with $T_{p}$ larger than $8 \mathrm{~s}$, the value chosen as a threshold in the algorithm of determination of swell events. The most likely number of swell events per year reaching the global coast (Fig. 2b) is found to be between 6 and 8 while the median duration of a swell event (Fig. 2c) is around $34 \mathrm{~h}$. The most probable median wave height arriving to the coastlines (Fig. 2d) was between 1 and $1.5 \mathrm{~m}$.

The regions where the swell events described above, from the CFSR hindcast (1979-2009), have originated are shown in Fig. 3 (note that the color scale of the Northern Hemisphere is smaller by a factor of 2.5 than the color scale of the Southern Hemisphere, as indicated in the color bar). This figure has been computed by adding up all of the daily maps of swell origins obtained by the procedure described in section $2 \mathrm{c}$ and then dividing by the number of years. The Southern Ocean completely dominates the map of the locations of swell generation with two different regions. The area of the main region (region 1; marked with a numeral 1 in Fig. 3), with the formation of more than 100 swell events per year, extends from $65^{\circ} \mathrm{W}$ to $70^{\circ} \mathrm{E}$ and from around $-38^{\circ}$ to $-58^{\circ} \mathrm{S}$; the second region (marked 2 ) with more than 80 swell events per year, is located southeastward of Australia and New Zealand. The number of swell events generated in the Northern Hemisphere is considerably smaller (maximum values do not exceed 50 events per year). The most important generation region in the Northern Hemisphere is observed in the North Pacific Ocean (region 3; $150^{\circ}-$ $\left.170^{\circ} \mathrm{E}, 40^{\circ} \mathrm{N}-50^{\circ} \mathrm{S}\right)$. The last and weakest generation zone identified is located in the North Atlantic Ocean, close to the eastern coast of the United States (region $4 ; 75^{\circ}-55^{\circ} \mathrm{W}, 30^{\circ} \mathrm{N}-40^{\circ} \mathrm{S}$ ), with maximum values of around 28 events per year.

Swells generated in each of these four regions (delimited by black thick lines in Fig. 3) may impact different sectors of the coastlines; likewise, for particular coastal points we can identify the regions with corresponding swell generation (Fig. 4). From a coastal

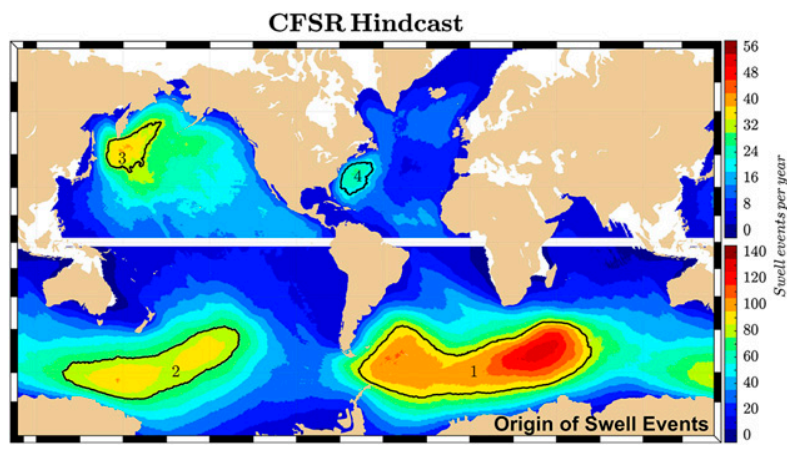

FIG. 3. Origin of formation of swell events arriving to the global coastlines. Note the different color scales of the Northern and Southern Hemispheres. The black contours indicate 85, 75, 32, and 20 swell events for regions $1,2,3$, and 4 , respectively. 


\section{CFSR Hindcast}

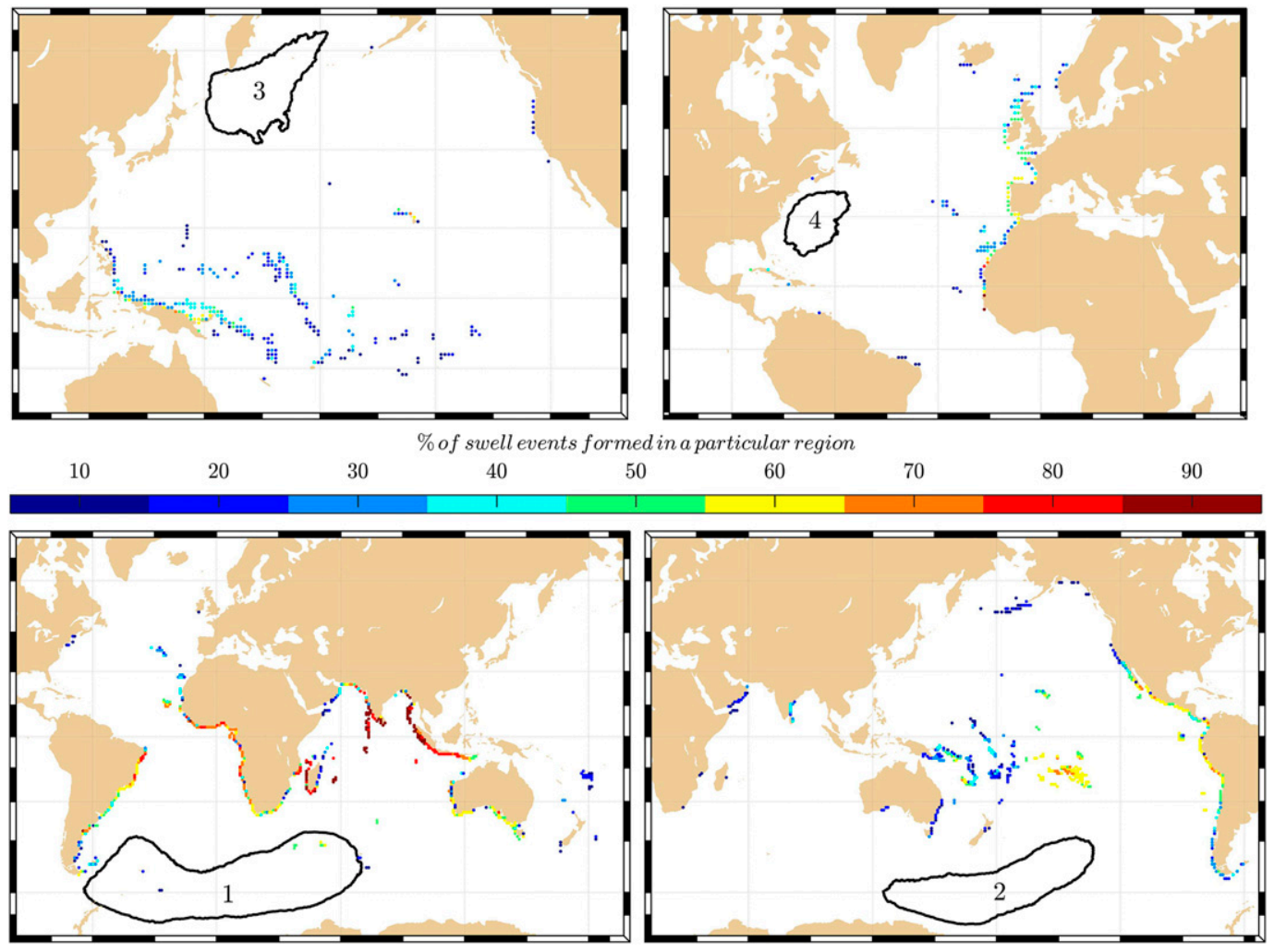

FIG. 4. Percentage of swell events reaching the coastlines and originating in each of the main formation regions.

perspective, it is the latter metric what matters, so we adopt the position of an observer at the coast to describe the characteristics of the swells. For example, more than $80 \%$ (even more than $95 \%$ ) swell events reaching the western coast of Madagascar, the western coast of India, the Maldives, and the coastlines from Bangladesh $\left(22^{\circ} \mathrm{N}\right)$ to Timor $\left(123^{\circ} \mathrm{E}-10^{\circ} \mathrm{S}\right)$ were formed inside region 1 . Between $60 \%$ and $80 \%$ of the swell events affecting the western coast of Africa, the coast of Brazil (from $5^{\circ}$ to $25^{\circ} \mathrm{S}$ ), and the southern coasts of the Cape Verde islands were also formed inside this region. It is also significant that between $60 \%$ and $70 \%$ of the events registered in French Polynesia and on the western coast of America, from Mexico $\left(30^{\circ} \mathrm{N}\right)$ to Peru $\left(20^{\circ} \mathrm{S}\right)$, were generated in region 2 . These high percentages of swell events reaching a coastal point generated inside a particular region are not observed in the two regions of the Northern Hemisphere, with the exception of the coast of Portugal and Spain with a percentage of swell events generated inside region 4 of $50 \%-60 \%$.

\section{b. Hindcast versus historical runs of coastal waves}

Prior to the quantification of projected changes in coastal swell waves, we have assessed the performance of the CMIP5 historical runs of each model in comparison to the CFSR hindcast, in order to ensure that climate runs provide statistically consistent results. In Fig. 5, we show the ensemble mean (Figs. 5a,c,e,g) and ensemble standard deviation (Figs. 5b,d,f,h) of the difference between all historical runs and the CFSR hindcast at each coastal point for the same metrics shown in Fig. 2, namely, the most probable peak period (Figs. 5a,b), the number of swell events (Figs. 5c,d), the swell duration (Figs. 5e,f), and the median swell significant wave height (Figs. 5g,h).

Overall, the CMIP5 historical runs have smaller most probable peak periods (up to $1.6 \mathrm{~s}$ less; Fig. 5a). The largest differences are found in the Pacific and Indian Ocean islands and in the North Atlantic islands, which are also the regions with larger standard deviation among models. The comparison of each individual historical run are shown in online supplemental Fig. SM3, showing the consistency among models, except for the CNRM-CM5. For the number of swell events (Fig. 5c), larger differences are found at low latitudes, especially along the continental eastern coasts (between 2 and 8 fewer events per year) and in oceanic islands, irrespective of their location, where differences are positive. 

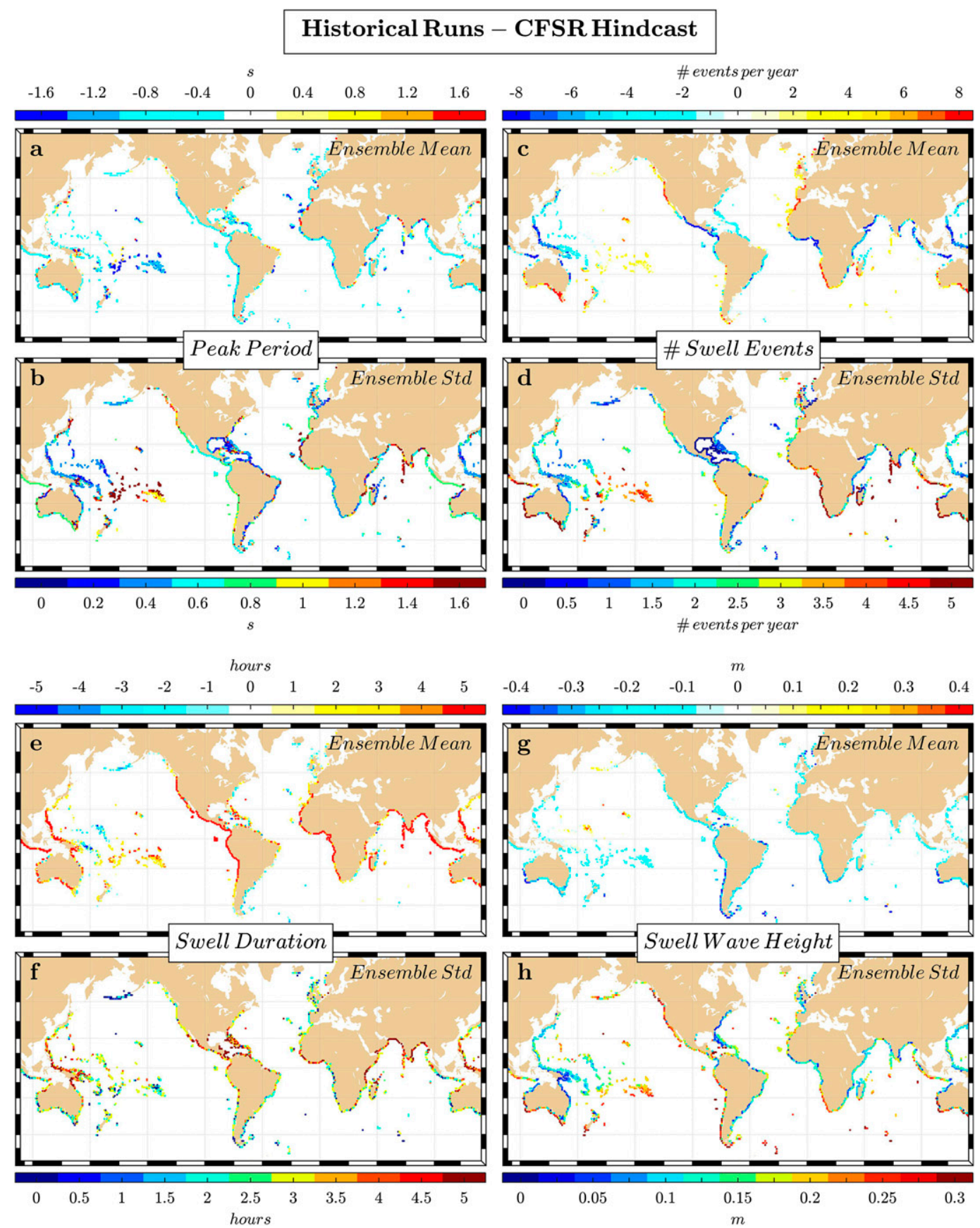

FIG. 5. Comparison between CFSR hindcast and climate model historical runs: (a) ensemble mean and (b) ensemble standard deviation of the differences in the swell peak period. (c),(d) As in (a) and (b), but for the differences in the number of swell events per year. (e),(f) As in (a) and (b), but for the differences in swell duration. $(\mathrm{g}),(\mathrm{h})$ As in (a) and (b), but for the differences in swell significant wave height.

Again, most models are in agreement (Fig. SM4 in the online supplemental material). The differences in swell duration (Fig. 5e) show a homogeneous pattern with CMIP5 historical runs having longer durations (around $3 \mathrm{~h}$ ) almost everywhere. And finally, the ensemble mean of the difference in median wave height between the historical runs and the CFSR hindcast (Fig. $5 \mathrm{~g}$ ) is negative almost everywhere, excluding the Hawaiian Islands and the northeastern islands of the Pacific Ocean, meaning that the CMIP5 models underestimate the wave height of the swell events. The spatial distribution of the median wave height was similar for all eight 


\section{Historical Runs}
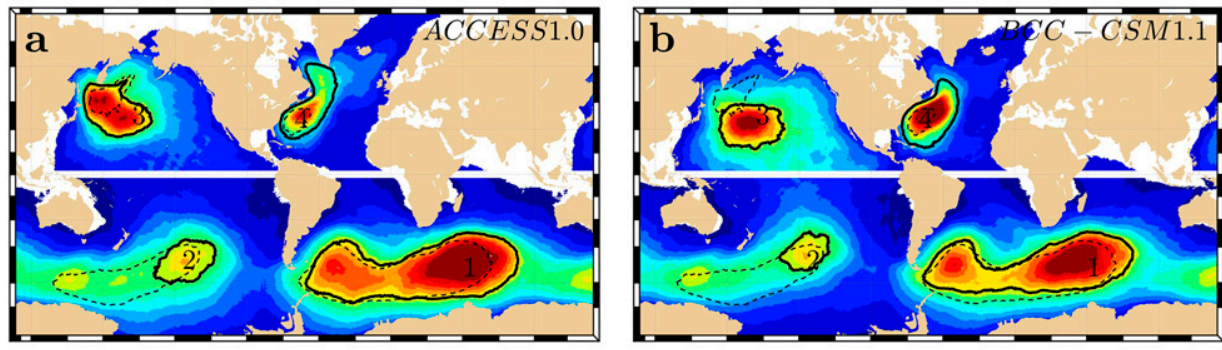

$56 / 140$
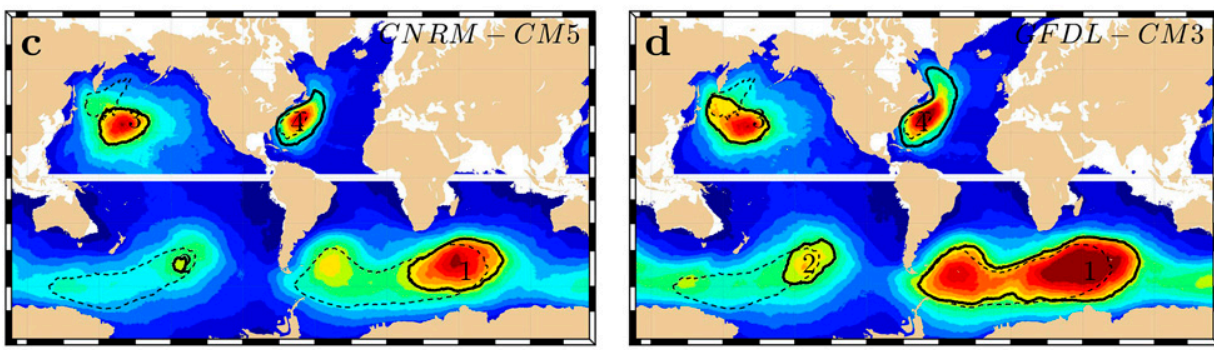

$40 / 100$
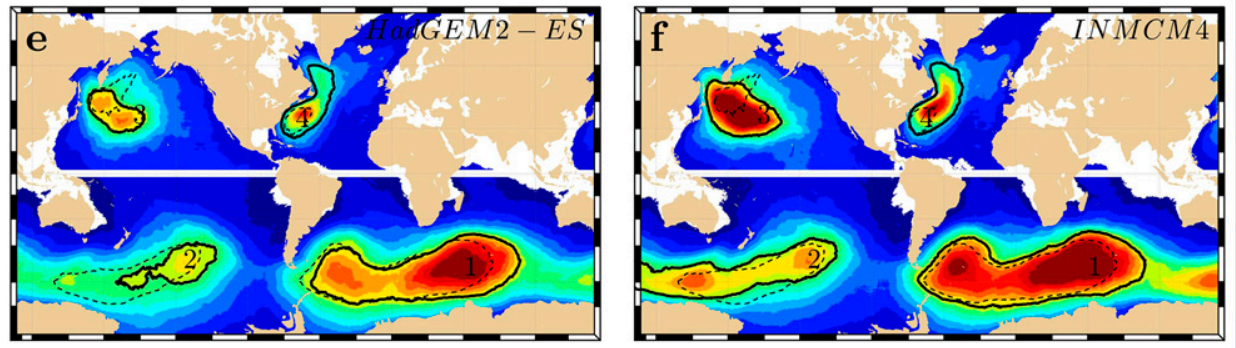

$48 / 120$
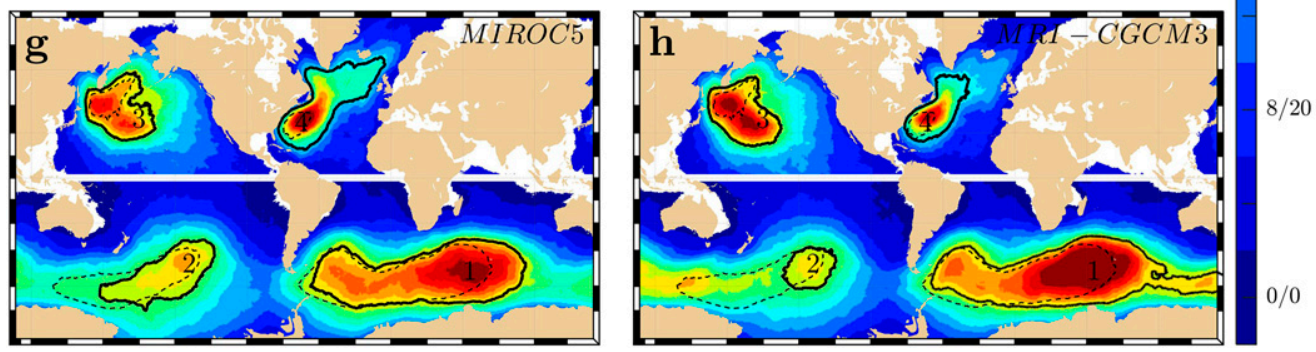

FIG. 6. Origin of formation of swell events arriving to the global coastlines for each historical run of the CMIP5 model ensemble. The color scale corresponding to the Northern Hemisphere $(\mathrm{NH})$ has been multiplied by a factor of 2.5 to enable a better visualization. The black thick contours indicate $85,75,32$, and 20 swell events for regions 1 , 2,3 , and 4 , respectively. Thin dashed black contours indicate the equivalent region determined for the CFSR hindcast in Fig. 3.

CMIP5 model historical runs except again for CNRMCM5 (Fig. SM6 in the online supplemental material).

The maps of the origin of swell events for the historical period of the eight CMIP5 models are shown in Fig. 6 (and online supplemental Fig. SM7 for the difference with the CFSR hindcast). The results show an increase in the number of events with some particularities for each region and model. Region 1, delimited by the contour line of 85 events per year and located south of Africa (thick black lines), coincides with CFSR (dashed line) for all models with the exception of the CNRM-CM5 model (Fig. 6c). In this particular model, the longitudinal extend of this region was reduced approximately to one-half because of a smaller number of events originated between South America and Africa (Fig. SM7c). The part of this region with larger values appears consistently slightly shifted eastward in all the models. It is worth mentioning that, although the geographical coverage of this region was similar between the historical runs and the CFSR hindcast, the number of swell events inside this region was considerably larger for all the models, reaching values larger than 140 events per year (see that all of the anomalies inside this region are positive in Fig. SM7 with the exception of 
CNRM-CM5). Region 2 (contour line of 75 events per year) is the one that presents larger differences between the historical runs and the CFSR hindcast and between the models themselves. All of the models, with the exception of INM-CM4, show a smaller area for region 2, which has almost disappeared in the CNRM-CM5 model. The reason for this difference is found in an overall reduction of the number of swell events coming from this region that causes the 75-events-per-year contour line to surround only the maximum located between Australia and South America (Fig. SM7). The two regions located in the Northern Hemisphere (regions 3 and 4) show a considerably larger number of swell events per year in the historical runs. Region 3 increased its size and maximum value and shifted southeast. Region 4 has doubled the number of events per year in the historical runs (from 28-32 to more than 56) and has become of the same magnitude as region 3 . This increase in the number of events in region 4 was translated into an increase of its extension northward, covering in all of the historical runs the area located between North America and Greenland.

\section{c. Projected changes in coastal swell waves}

Projected changes of the characteristics of the swell events along the coasts are mapped in Fig. 7 for the case of the RCP8.5 scenario and for the end of the twentyfirst century (2081-2100). This is the case in which the largest changes are expected. The maximum projected changes in the peak period (Fig. 7a) by the model ensemble are around $1 \mathrm{~s}$ of increase or decrease (depending on the region), which translates into a maximum relative change ranging from $6 \%$ to $12.5 \%$ (computed for peak periods of 15 and $8 \mathrm{~s}$, respectively). The different projected shifts in the peak period affect coastal regions consistent with those impacted by swell areas of generation as distributed in Fig. 6. For example, a peak period increase is observed in the western coast of Africa from Cape Town to the Cape Verde Islands while there is a peak period decrease from these islands northward, including all the European coast. This polarization is explained because swells affecting the African coast from Cape Verde Islands southward are formed mainly in region 1 , whereas those along the European coasts are mostly linked to region 4 . The same argument is valid for the coastal points that have regions 2 and 3 of swell origin. The western coast of America and the southern part of French Polynesia show an increase of the peak period because they are regions that receive eastern propagating swells formed in region 2 . The coastal points that receive swell generated in region 3 (all of the northern part of the Pacific islands between $20^{\circ} \mathrm{N}$ and $20^{\circ} \mathrm{S}$ ) presented a decrease of the peak period.
These results suggest that the eastward-propagating swell generated in the Southern Ocean will experience an increase of peak period while the swell generated in the Northern Hemisphere is expected to decrease its peak period.

The number of swell events per year (Fig. 7c) shows an overall decrease along most continental coasts (excluding the southwestern coast of South America). The major changes are observed in the Pacific islands between $20^{\circ} \mathrm{N}$ and $20^{\circ} \mathrm{S}$ and the Indian Ocean islands (including Maldives) where an increase of the number of swell events (between $12 \%$ and $20 \%$ ) is observed. The swell duration (Fig. 7e) is spatially heterogeneous (see the individual model fields in online supplemental Fig. SM11) and shows an overall increase between $2 \%$ and $10 \%$. Finally, changes in the significant wave height of the swell events (Fig. $7 \mathrm{~g}$ ) are around $\pm 5 \mathrm{~cm}$, representing a relative change smaller than $5 \%$ along $75 \%$ of the world coastlines and a relative change smaller than $10 \%$ along $97 \%$ of the coastlines. The regions with larger increase in wave height (between 5 and $10 \mathrm{~cm}$ ) are found in the regions closer to the Southern Ocean such as the southern part of Australia and New Zealand, the southernmost part of America and Africa, and the southernmost islands of the Atlantic and the Indian Ocean. The projected changes in the wave energy flux (not shown) show a pattern similar to the significant wave height map. The largest increases of wave energy flux are given in the southern coast of Australia, French Polynesia, the western coast of Central America, the southernmost part of America, and the western coast of Africa from the Cape Verde Islands southward. On the other hand, the largest decreases are observed in the western African coast northward of the Cape Verde Islands, the European coasts, and the western coasts of the Pacific Ocean, including the Pacific islands mainly located in the Northern Hemisphere.

Together with the ensemble average of projections we provide the ensemble standard deviations in Fig. 7. There are two remarkable features: first, because projected changes are small in magnitude, the model spreading (measured as the difference between the absolute value of the ensemble mean difference and the ensemble standard deviation of the difference; Fig. SM8 in the online supplemental material) is generally larger. And second, despite the disagreement in magnitude, the spatial patterns among models are consistent. To explore the cause of these patterns of change we have compared the maps of the number of swell events per year generated by the historical runs and by the RCP8.5 runs for the end of the twenty-first century for each individual model (Fig. 8). In the Southern Hemisphere (note that color scales in Fig. 8 

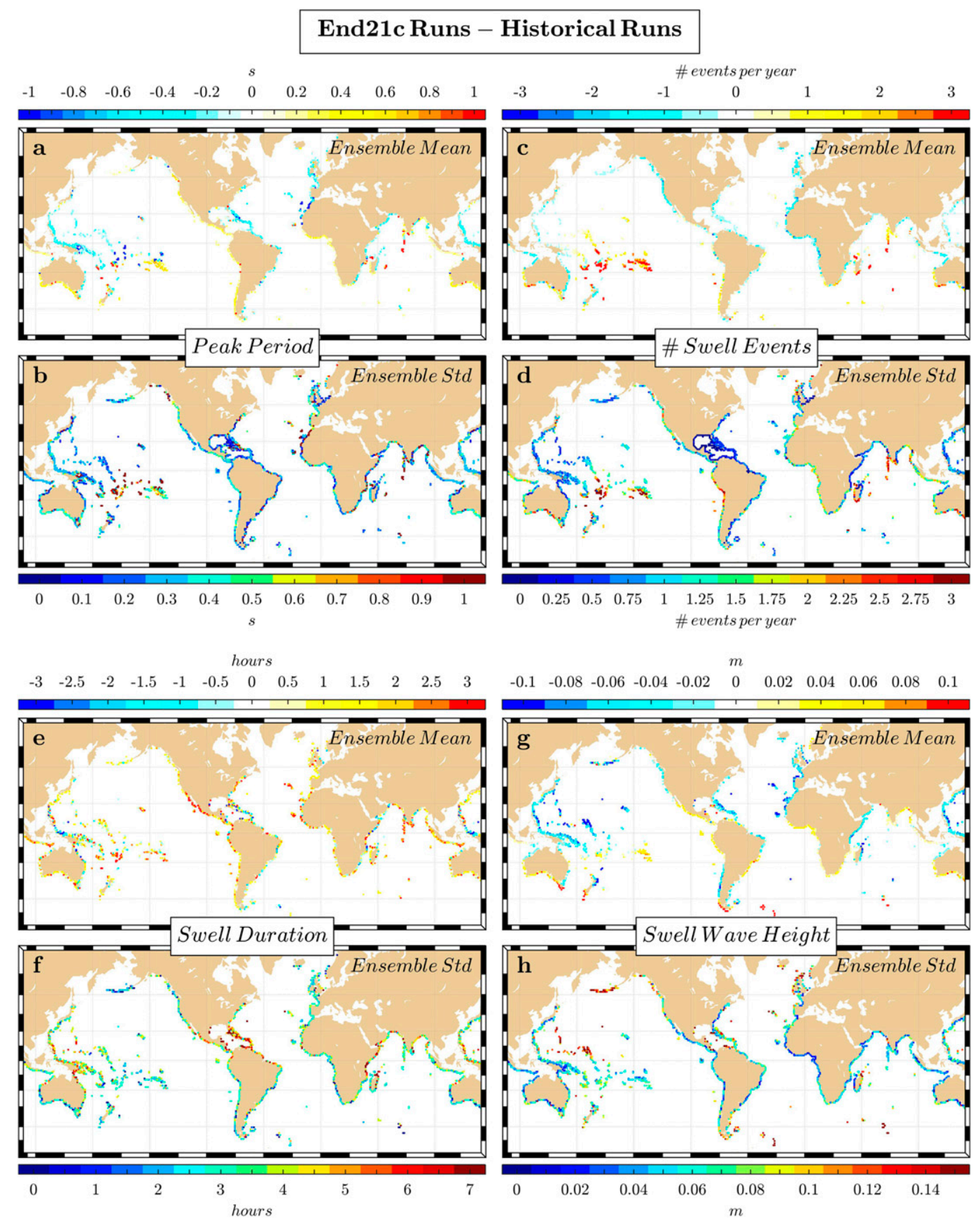

FIG. 7. Projected changes in swell parameters: (a) ensemble mean and (b) ensemble standard deviation of the change in swell peak period between the RCP8.5 runs for the late twenty-first century of the CMIP5 models and the corresponding historical run. (c),(d) As in (a) and (b), but for the number of swell events per year. (e),(f) As in (a) and (b), but for swell duration. (g),(h) As in (a) and (b), but for the swell significant wave height.

are different for each hemisphere), all of the models show a latitudinal dipole structure, with an increase of number of swell events close to Antarctica and a decrease northward of $53^{\circ} \mathrm{S}$. In the Northern Hemisphere, all of the models project a generalized decrease of the number of swell events except in the region around the
Kamchatka Peninsula. Comparing the different models among them, it can be seen that CNRM-CM5 (Fig. 8c) predicts smaller changes, whereas GFDL-CM3 (Fig. 8d) has larger differences in the number of swell events by the end of the century. This latitudinal structure described above is highlighted with a zonal 


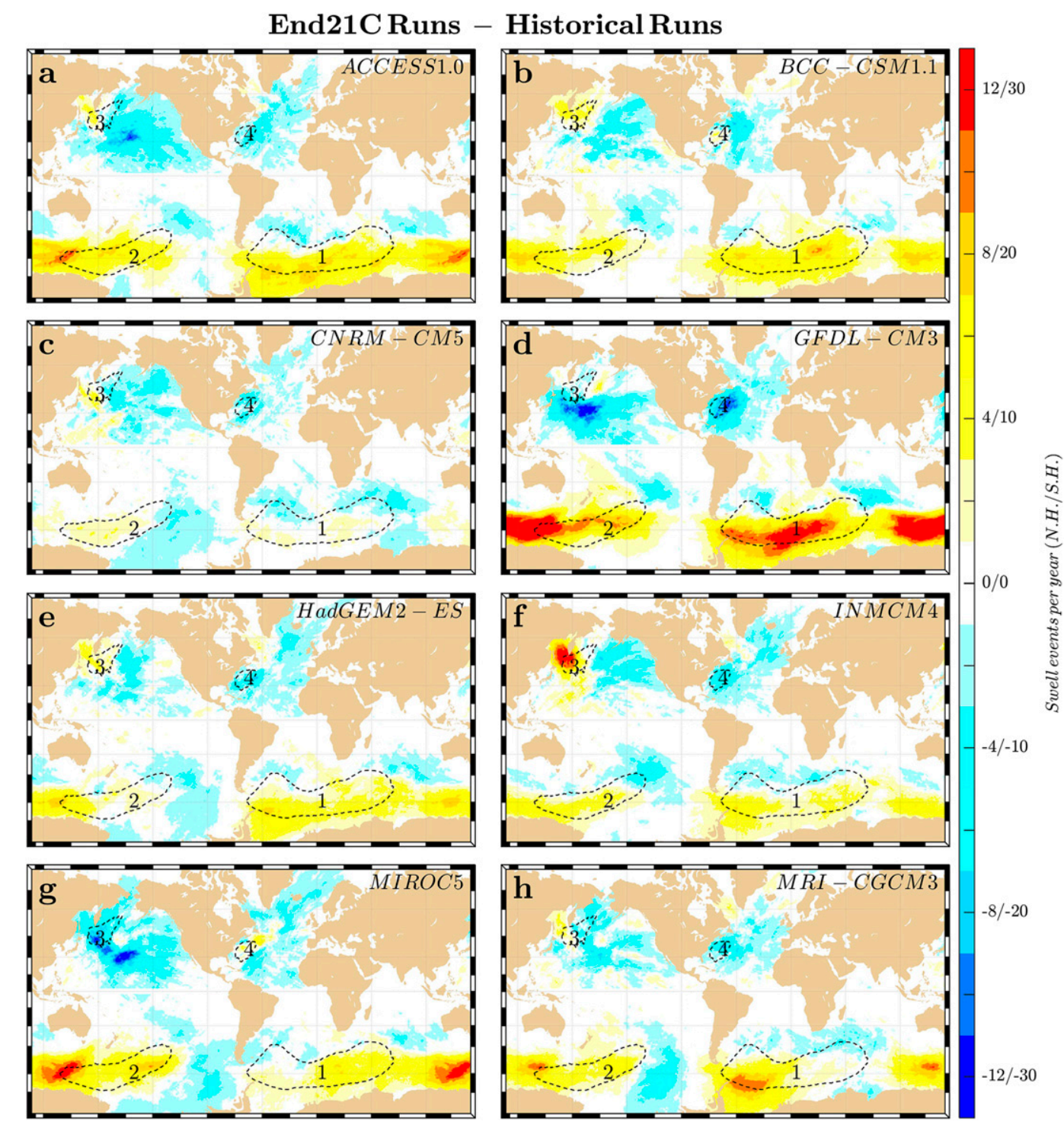

FIG. 8. Projected changes in the region of swell formation under RCP8.5 scenario by the late twenty-first century. The color scale corresponding to the Northern Hemisphere (NH) has been multiplied by a factor of 2.5 to enable a better visualization. Thin dashed black contours indicate the regions determined for the CFSR hindcast in Fig. 3.

mean of the maps of the differences for each model (Fig. 9). The ensemble zonal mean (thick black line) clearly shows this latitudinal dipole in the Southern Hemisphere between $30^{\circ}$ and $75^{\circ} \mathrm{S}$, with a maximum increase value of eight-nine swell events per year around $60^{\circ} \mathrm{S}$ and a decrease of around two events per year around $40^{\circ} \mathrm{S}$. The increase or decrease in the number of swell events generated on those latitudes respectively represents around $11 \%$ more or $4 \%$ fewer) events per year with respect to the historical runs. As mentioned above, the Northern Hemisphere presents a generalized decrease of the number of swell events, with its maximum decrease $(-2.5$ events per year, which represents a decrease of $11 \%$ with respect the historical runs) located around $35^{\circ} \mathrm{N}$.

\section{Summary and discussion}

We have focused our analyses on the swell component of the ocean wind-waves, which is globally the dominant contributor of the coastal wave climate (Semedo et al. 2011). We have, for the first time, unequivocally differentiated swells from the wind sea along the coastlines, at the global scale, taking advantage of the their dispersive nature, with a method that is not influenced by the choice of the spectral partitioning scheme (Portilla 


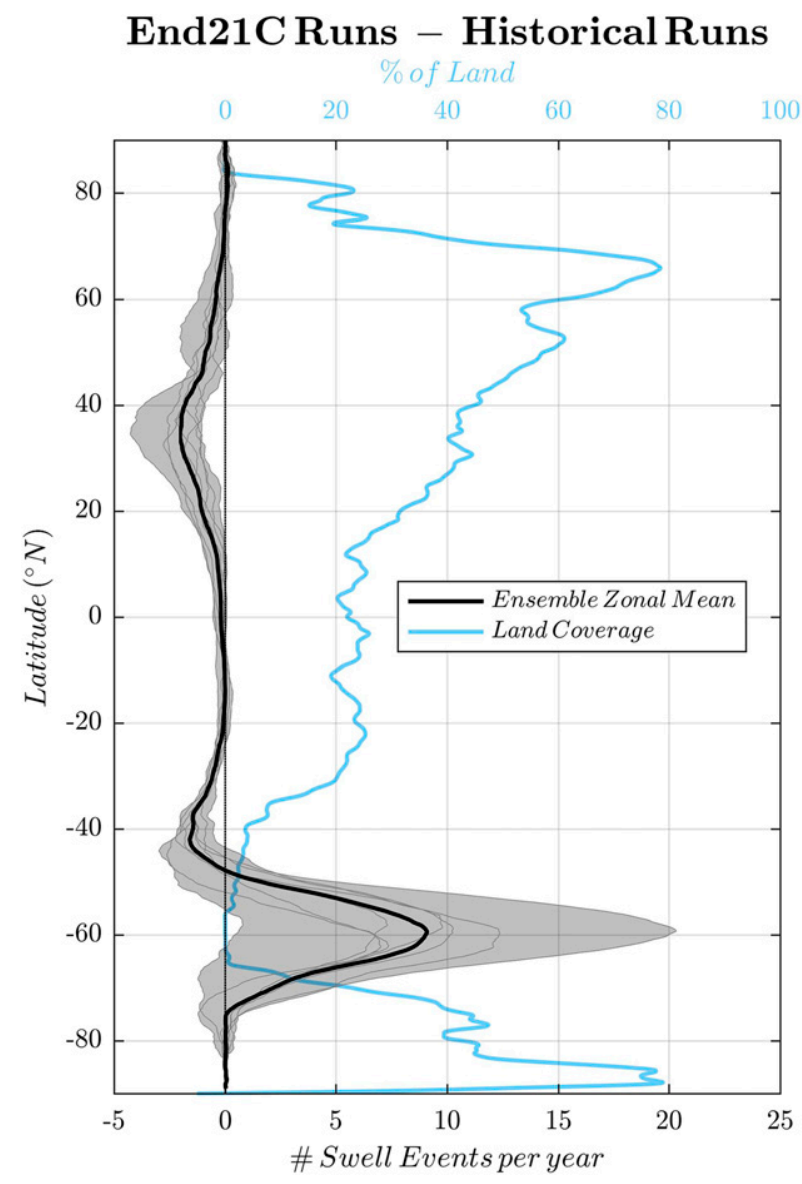

FIG. 9. Zonally averaged projected changes in the swell formation areas shown in Fig. 8. The model ensemble mean is shown with a black thick line, and individual models are represented by thin gray lines. The thick light-blue line shows the percentage of Earth covered by land at each latitude.

2012). This has allowed us to identify the time and origin of formation of swell events reaching the global coasts in hindcast data as well as in future climate projections. We would like to recall here that our method selects only those swell events reaching the coastlines that arrive directly (without path modifications) from their formation region. Earlier works have investigated swell generation and propagation over large distances using observations. For example, Young et al. (2013) quantified the swell decay rates in the Southern Ocean using altimetry measurements. Also based on remote sensing wave observations, Wang et al. (2016) identified the origin of swells in the global ocean. However, to our knowledge, this is the first time that this type of analysis 1 ) has been performed over a long period of various decades, 2) has investigated the effect of global warming, and 3) has been presented from a coastal perspective.

Present-day wave conditions provided by the CFSR hindcast have been used to explore the characteristics of the swell events as they reach the global coastlines. We have shown that the regions affected by a larger number of swell events are the intertropical areas of the western coasts, in line with the results presented in Semedo et al. (2011), and that these are also the regions with events of longer duration. The intertropical islands are the areas with higher values of the swell characteristics, irrespective of their location: for example, French Polynesia in the Pacific Ocean, the Cape Verde Islands in the Atlantic, or the Maldives in the Indian Ocean. In these regions we found longer peak periods, large number of swell events, longer duration, and large median significant wave height in comparison to the rest of the world coastlines. The hindcast has also allowed us to identify the main swell formation regions, with two in each hemisphere. The formation regions located in the Southern Ocean have been found to originate a larger number of swells, with more than 2 times (or even 4 times) as many swells as those events generated in the Northern Hemisphere. This result is in agreement with Fan et al. (2014) and Semedo et al. (2011), who showed that the Southern Ocean swells dominate the swell component in the global ocean.

Once the origin of the swells was identified, we explored changes in the formation regions and their consequent changes in the exposure of the global coastlines to remotely generated swells by the end of the present century. The set of wave climate models available shows overall agreement, with similar patterns of projected variations in wave characteristics. The only exception that we found is the CNRM-CM5 model, which shows very small relative changes in wave projections; this one is also the model with the largest differences between its historical run and the CFSR hindcast (not only in the magnitudes of the swell events but also in the delimitation of the formation regions). This last result is in agreement with Hemer and Trenham (2016), who state that "CNRM-CM5 is the model which consistently underperforms the other models" (p. 197). By the end of the twenty-first century, the model ensemble projections under RCP8.5 show an increase of the peak period in the coastal points affected by the eastern-propagating swells generated in the Southern Ocean and a decrease along the coasts receiving swells developed in the Northern Hemisphere. The number of swell events is projected to diminish in general, except in the Pacific islands, Maldives, and the Pacific coast of South America, whereas the changes in the swell duration present a heterogeneous pattern and no general conclusion can be drawn. Regarding the intensity of swell events, an increase (decrease) of swell significant wave height is observed along the coasts of the Southern (Northern) 
Hemisphere, with the exception of South America. However, it must be remarked that the model spreading around the ensemble mean is, in general, larger than the projected changes. Nevertheless, when analyzing the future changes of the main swell properties for individual models, it is observed that all of them show a similar spatial pattern with changes of similar magnitude. Again, the CNRMCM5 model stands out as the model with higher differences with the rest and with smaller expected changes. On the other hand, the GFDL CM3 model is the one with the largest changes in magnitude.

Our analysis of the changes in the formation regions of the swell events points toward a poleward shift of these regions under the RCP8.5 scenario. This projected shift of the area of maximum swell generation in the Southern Hemisphere, together with its intensification, is consistent with a poleward movement and intensification of the wind belt that has been previously reported and related to a continuous shift of the southern annular mode (SAM) toward its positive phase under future climates (Thompson et al. 2011; Fan et al. 2014; Arblaster et al. 2011). Likewise, a similar poleward movement of the midlatitude cyclones tracks has been projected in the Northern Hemisphere (Fan et al. 2014; Meehl et al. 2007). Interestingly, in the Northern Hemisphere the changes in the swell fields are not that evident: only a decrease of the number of swell events is observed that is located at the same latitude as the minimum found in the Southern Hemisphere (around $40^{\circ}$ ). We hypothesize that the reason for this lack of response in the Northern Hemisphere is related to the smaller fraction of sea with respect to land at the latitude where this maximum is expected (around $60^{\circ}$; see the blue line in Fig. 9). In the case of the Northern Hemisphere, between $60 \%$ and $80 \%$ of the area located around $60^{\circ} \mathrm{N}$ is land, whereas this fraction is $0 \%$ in the Southern Hemisphere. We have not reported changes in the tropical regions because, given our requirements for the selection of swell events, the main regions of formation are located at midlatitudes and, thus, no conclusion can be drawn for other regions.

Acknowledgments. This study was supported by the ERA4CS INSeaPTION project (grant number: 690462 and PCIN-2017-038) funded by the Spanish Ministerio de Economía, Industria y Competitividad - Agencia Estatal de Investigación.

\section{REFERENCES}

Arblaster, J. M., G. A. Meehl, and D. J. Karoly, 2011: Future climate change in the Southern Hemisphere: Competing effects of ozone and greenhouse gases. Geophys. Res. Lett., 38, L02701, https://doi.org/10.1029/2010GL045384.
Ardhuin, F., B. Chapron, and F. Collard, 2009: Observation of swell dissipation across oceans. Geophys. Res. Lett., 36, L06607, https://doi.org/10.1029/2008GL037030.

Cavaleri, L., B. Fox-Kemper, and M. Hemer, 2012: Wind waves in the coupled climate system. Bull. Amer. Meteor. Soc., 93, 1651-1661, https://doi.org/10.1175/BAMS-D-11-00170.1.

Fan, Y., S.-J. Lin, S. M. Griffies, and M. A. Hemer, 2014: Simulated global swell and wind-sea climate and their responses to anthropogenic climate change at the end of the twenty-first century. J. Climate, 27, 3516-3536, https://doi.org/10.1175/ JCLI-D-13-00198.1.

Gulev, S. K., and V. Grigorieva, 2006: Variability of the winter wind waves and swell in the North Atlantic and North Pacific as revealed by the voluntary observing ship data. J. Climate, 19, 5667-5685, https://doi.org/10.1175/JCLI3936.1.

,,-- A. Sterl, and D. Woolf, 2003: Assessment of the reliability of wave observations from voluntary observing ships: Insights from the validation of a global wind wave climatology based on voluntary observing ship data. J. Geophys. Res., 108, 3236, https://doi.org/10.1029/2002JC001437.

Hemer, M. A., and C. E. Trenham, 2016: Evaluation of a CMIP5 derived dynamical global wind wave climate model ensemble. Ocean Modell., 103, 190-203, https://doi.org/10.1016/j.ocemod. 2015.10.009.

_ J. A. Church, and J. R. Hunter, 2010: Variability and trends in the directional wave climate of the Southern Hemisphere. Int. J. Climatol., 30, 475-491, https://doi.org/10.1002/joc.1900.

- Y. Fan, N. Mori, A. Semedo, and X. L. Wang, 2013a: Projected changes in wave climate from a multi-model ensemble. Nat. Climate Change, 3, 471-476, https://doi.org/10.1038/ nclimate1791.

_ J. Jatzfey, and C. E. Trenham, 2013b: Global dynamical projections of surface ocean wave climate for a future high greenhouse gas emission scenario. Ocean Modell., 70, 221245, https://doi.org/10.1016/j.ocemod.2012.09.008.

- C. E. Trenham, T. Durrant, and D. Greenslade, 2015: CAWCR global wind-wave 21 st century climate projections (v1). CSIRO Data Access Portal, accessed January 2018, https://doi.org/10.4225/08/55C991CC3F0E8.

Meehl, G., and Coauthors, 2007: Global climate projections. Climate Change 2007: The Physical Science Basis, S. Solomon et al., Eds., Cambridge University Press, 747-845.

Mori, N., T. Shimura, T. Yasuda, and H. Mase, 2013: Multi-model climate projections of ocean surface variables under different climate scenarios-Future change of waves, sea level and wind. Ocean Eng., 71, 122-129, https://doi.org/10.1016/j.oceaneng. 2013.02.016.

Pérez, J., F. J. Méndez, M. Menéndez, and I. J. Losada, 2014: ESTELA: A method for evaluating the source and travel time of the wave energy reaching a local area. Ocean Dyn., 64, 1181-1191, https://doi.org/10.1007/s10236-014-0740-7.

Portilla, J., 2012: Storm-source-locating algorithm based on the dispersive nature of ocean swells. Avances, 4 (1), C22-C36, https://www.usfq.edu.ec/publicaciones/avances/archivo_de_ contenidos/Documents/volumen_4/Avances_2012_vol4_n1_ C22-C36.pdf.

Saha, S., and Coauthors, 2010: The NCEP Climate Forecast System Reanalysis. Bull. Amer. Meteor. Soc., 91, 1015-1058, https:// doi.org/10.1175/2010BAMS3001.1.

Semedo, A., K. Sušelj, A. Rutgersson, and A. Sterl, 2011: A global view on the wind sea and swell climate and variability from ERA-40. J. Climate, 24, 1461-1479, https://doi.org/10.1175/ 2010JCLI3718.1. 
Small, C., and R. J. Nicholls, 2003: A global analysis of human settlement in coastal zones. J. Coast. Res., 19, 584-599, http:// www.jstor.org/stable/4299200.

Thompson, D. W. J., S. Solomon, P. J. Kushner, M. H. England, K. M. Grise, and D. J. Karoly, 2011: Signatures of the Antarctic ozone hole in Southern Hemisphere surface climate change. Nat. Geosci., 4, 741-749, https://doi.org/10.1038/ngeo1296.

Tolman, H., 2009: User manual and system documentation of WAVEWATCH III version 3.14. NOAA/NWS/NCEP/MMAB Tech. Note 276, 194 pp. + appendices.
Wang, X., H. Jiang, G. Chen, and F. Yu, 2016: Identifying storminduced wave origins using SAR wave mode data. Sci. China Earth Sci., 59, 1971-1980, https://doi.org/10.1007/s11430-0155478-3.

Young, I. R., 1999: Seasonal variability of the global ocean wind and wave climate. Int. J. Climatol., 19, 931-950, https://doi.org/10.1002/ (SICI)1097-0088(199907)19:9<931::AID-JOC412>3.0.CO;2-O.

A. V. Babanin, and S. Zieger, 2013: The decay rate of ocean swell observed by altimeter. J. Phys. Oceanogr., 43, 2322-2333, https://doi.org/10.1175/JPO-D-13-083.1. 